\title{
Clinical significance of the cachexia index in patients with small cell lung cancer
}

Se-ll Go ${ }^{1+}$, Mi Jung Park ${ }^{2 \dagger}$ and Gyeong-Won Lee $3^{3^{*}}$

\begin{abstract}
Background: Cancer cachexia worsens the treatment outcomes of patients with small-cell lung cancer (SCLC). However, no reliable biomarker of cancer cachexia is yet known.

Methods: We retrospectively evaluated male SCLC patients who received induction chemotherapy or concurrent chemoradiotherapy. The cachexia index (CXI) was calculated as skeletal muscle index $\times$ serum albumin level (g/dL)/ neutrophil-to-lymphocyte ratio. The CXI cutoff according to tumor stage was determined based on a timedependent receiver operating characteristic curve, and all patients were divided into low- and high-CXI groups.

Results: Of 267 patients, 83 and 24 patients with limited-stage disease (LD) and 123 and 37 patients with extensivestage disease (ED) were assigned to the high- and low-CXI groups, respectively. Only one of 24 patients (4.2\%) with LD in the low-CXI group achieved a complete response (CR), whereas 30 of 83 patients (36.1\%) with LD in the high$C X I$ group achieved CRs $(p=0.004)$. More low-CXI patients required early discontinuation of treatment because of treatment-related toxicity compared to the high-CXI patients (37.5\% vs. $16.9 \%$, respectively, $p=0.030$, for LD patients; $27.0 \%$ vs. $11.4 \%$, respectively, $p=0.019$, for ED patients). The median progression-free survival (PFS) and overall survival (OS) were significantly shorter in the low-CXI group than the high-CXI group (6.3 vs. 11.1 months and 7.5 vs. 20.6 months, respectively, both $p<0.001$ for LD patients; 2.9 vs. 6.3 months and 5.8 vs. 12.8 months, respectively, both $p<0.001$, for ED patients). On multivariate analysis, low-CXI status was an independent poor prognostic factor for both PFS and OS regardless of the tumor stage.
\end{abstract}

Conclusion: A low CXI was associated with treatment intolerance, poor treatment response rate, and poor prognosis in SCLC.

Keywords: Small cell lung carcinoma, Cachexia, Sarcopenia, Serum albumin, Biomarker

\section{Background}

Small cell lung cancer (SCLC) is a highly aggressive disease characterized by rapid tumor growth, early widespread dissemination, and a high probability of relapse $[1,2]$. Although the response duration is short, etoposide or irinotecan plus platinum-based chemotherapy with or

\footnotetext{
*Correspondence: brightree24@gmail.com

†Se-ll Go and Mi Jung Park contributed equally to this work.

${ }^{3}$ Division of Hematology-Oncology, Department of Internal Medicine, Institute of Health Science, Gyeongsang National University Hospital,

Gyeongsang National University College of Medicine, 79 Gangnam-ro, Jinju 52727, Republic of Korea

Full list of author information is available at the end of the article
}

without concurrent radiotherapy is associated with a high response rate and prolongs survival [3-5]. The addition of immunotherapy to chemotherapy further improved the treatment outcomes of patients with extensive-stage disease (ED) [6, 7]. However, elderly patients or those with poor performance status (PS) experience more treatment-related toxicity and tend to be unable to undergo optimal treatment [8-10]. As the prognosis of SCLC patients who fail to complete treatment is extremely poor, those who cannot tolerate induction chemotherapy should be identified and treated with intensive supportive care.

(c) The Author(s). 2021 Open Access This article is licensed under a Creative Commons Attribution 4.0 International License, which permits use, sharing, adaptation, distribution and reproduction in any medium or format, as long as you give appropriate credit to the original author(s) and the source, provide a link to the Creative Commons licence, and indicate if changes were made. The images or other third party material in this article are included in the article's Creative Commons licence, unless indicated otherwise in a credit line to the material. If material is not included in the article's Creative Commons licence and your intended use is not permitted by statutory regulation or exceeds the permitted use, you will need to obtain permission directly from the copyright holder. To view a copy of this licence, visit http://creativecommons.org/licenses/by/4.0/ The Creative Commons Public Domain Dedication waiver (http://creativecommons.org/publicdomain/zero/1.0/) applies to the data made available in this article, unless otherwise stated in a credit line to the data. 
Cancer cachexia (an ongoing loss of skeletal muscle mass that cannot be fully reversed by conventional nutritional support [11]) is associated with more treatment-related toxicity, a reduced quality of life, and poor prognosis [12-14]. In SCLC patients, weight loss is associated with a poor treatment response, decreased quality of life, and short survival [15-17]. Several biomarkers of cachexia, such as sarcopenia, cachexia score, and nutritional indices, have been suggested to be prognostic in SCLC patients [18-22]. The cachexia index (CXI) is a novel measure of cachexia in patients with advanced non-small cell lung cancer and non-Hodgkin's lymphoma [23, 24]. The CXI considers the skeletal muscle index (SMI), serum albumin level, and neutrophil-to-lymphocyte ratio (NLR), and may thus comprehensively reflect cachectic status. Currently, any role for the CXI in SCLC remains unclear. Therefore, we investigated whether the CXI reflected the prognosis and treatment outcomes of SCLC patients.

\section{Methods \\ Patients}

From July 2006 to June 2020, all consecutive male SCLC patients receiving etoposide or irinotecan plus platinum combination chemotherapy as first-line treatment (with or without radiotherapy) in a single institution were retrospectively reviewed. As the CXI cutoff likely differs according to sex because muscle mass varies by sex, female patients were excluded as the sample size was too small to determine their cutoff. Patients with another type of cancer and/or a serious active infection were excluded. Those for whom serum albumin levels and complete blood counts measured within 7 days before the first cycle of chemotherapy as well as baseline chest computed tomography (CT) scans were unavailable were excluded. The study was approved by the Institutional Review Board of Gyeongsang National University Hospital.

\section{Assessments}

Clinical, laboratory, and radiological data were extracted from electronic medical records. The CXI was calculated as SMI $\times$ serum albumin level $(\mathrm{g} / \mathrm{dL}) / \mathrm{NLR}$ [23]. We used the pectoralis major and minor muscles to measure the SMI based on a previously described method [19]. Briefly, the region of interest (ROI) was drawn freehand at the outermost border of the pectoralis muscles at the T4 level, and its area, ranging from -29 to $100 \mathrm{HU}$, was calculated via CT histogram analysis ("X section" analysis tool, Advantage Window 4.4; GE Healthcare, Milwaukee, WI, USA). The cross-sectional areas of the bilateral pectoralis muscles were separately calculated based on CT histograms. The average area was normalized to height $\left(\mathrm{m}^{2}\right)$; the SMI thus had the unit $\mathrm{cm}^{2} / \mathrm{m}^{2}$.
Underweight was defined as a body mass index $(\mathrm{BMI})<$ $18.5 \mathrm{~kg} / \mathrm{m}^{2}$ (the Asian criterion). The response to anticancer therapy was assessed using the Response Evaluation Criteria in Solid Tumors (RECIST) ver. 1.1 [25]. The objective response rate (ORR) was calculated as the proportion of patients who achieved complete response (CR) or partial response (PR). All eligible patients were included in the analyses of treatment response, progression-free survival (PFS), and overall survival (OS) regardless of whether their treatment response was evaluated radiologically. Therapy-related adverse events were assessed using the National Cancer Institute Common Toxicity Criteria for Adverse Events ver. 4.0. Treatmentrelated mortality (TRM) was defined as death from any cause other than cancer progression before 30 days after the last cycle of first-line chemotherapy. Early discontinuation of treatment was noted when first-line chemotherapy ceased because of treatment-related toxicity, regardless of the response to treatment.

\section{Statistical analysis}

The CXI cutoff was determined by maximizing the Youden index (the sum of sensitivity and specificity) for predicting 18- and 10-month survival in limited-stage disease (LD) and ED, respectively, using a timedependent receiver operating characteristic (ROC) curve [26]. Each survival time point for determining the cutoff was decided by considering historical data $[3,5,27,28]$. With reference to the cutoffs, patients were divided into low- and high-CXI groups. Correlations between dichotomous and continuous or categorical variables were explored using the Mann-Whitney U-test and the chisquared test as appropriate. OS was defined as the time from the first day of treatment to death or the last follow-up. PFS was calculated as the time from the first day of treatment to progression, death, or the last follow-up. The Kaplan-Meier method and the log-rank test were used to estimate survival data. A Cox's regression model was employed for multivariate analysis. All variables with $p$-values $<0.10$ on univariate analyses were included in the multivariate regression model. A two-sided $p$-value $<0.05$ was considered to indicate statistical significance. All statistical analyses were performed using R ver. 3.6.2 (R Foundation for Statistical Computing, Vienna, Austria) and STATA ver. 16.1 (College Station, TX, USA).

\section{Results}

\section{Patient characteristics}

The mean ( \pm standard deviation) and median (interquartile range) CXI values were $11.09( \pm 6.17)$ and 10.08 (6.30-14.24) for LD patients and $8.18( \pm 5.92)$ and 6.77 (3.94-11.06) for ED patients, respectively $(p<0.001)$. The area under the curve (AUC) (calculated using time- 
dependent ROC data) was 0.632 [95\% confidence interval (CI) 0.521-0.744] for LD and 0.665 (95\% CI $0.577-$ 0.753 ) for ED (Supplementary Fig. 1). The CXI cutoffs were 5.82 (sensitivity $35.1 \%$ and specificity $92.5 \%$ ) for LD and 3.83 (sensitivity $43.5 \%$ and specificity $90.9 \%$ ) for ED. In total, 83 and 24 patients with LD and 123 and 37 patients with ED were assigned to the high- and low-CXI groups, respectively.

Comparison of patient baseline characteristics between the high- and low-CXI groups are presented in Table 1. Among the LD patients, the median age was higher in the low-CXI group than in the high-CXI group (70.5 vs. 66 years, respectively, $p=0.033)$, whereas there was no difference between the two groups for ED patients. The proportion of patients classified as Eastern Cooperative Oncology Group (ECOG) PS 2-3 was higher in the low-CXI group than in the high-CXI group regardless of stage $(33.3 \%$ vs. $10.8 \%$, respectively, $p=0.008$, for LD patients; $40.5 \%$ vs. $20.3 \%$, respectively, $p=0.013$, for ED patients). Among ED patients, the low-CXI group received prophylactic cranial irradiation less frequently $(16.2 \%$ vs. $40.7 \%$, respectively, $p=0.006)$ and had a lower median BMI (21.0 vs. $22.6 \mathrm{~kg} / \mathrm{m}^{2}$, respectively, $p=0.007)$ compared to the high-CXI group.

\section{Treatment response}

Of 267 patients, 16 were not available for the radiological assessment of treatment response (Table 2). The ORRs in the low- and high-CXI groups were 79.2 and 95.2\% $(p=0.026)$ for LD patients and 54.1 and $85.4 \%$ $(p<0.001)$ for ED patients, respectively. Only one LD patient and no ED patient achieved a CR in the low-CXI group. All 33 patients who achieved a CR completed their planned treatments. When 51 patients who discontinued treatment early (because of toxicity or patient decision) or for whom the radiological treatment response was not assessed were excluded from the analysis, the ORR remained lower in the low-CXI group compared to the high-CXI group regardless of stage $(86.7 \%$ vs. $100.0 \%$, respectively, $p=0.031$, for LD patients; $66.7 \%$ vs. $86.2 \%$, respectively, $p=0.022$, for ED patients).

\section{Treatment-related toxicity}

Adverse treatment-related events are listed in Table 3. There were no significant differences in hematological

Table 1 Comparison of baseline characteristics between the high- and low-CXI groups

\begin{tabular}{|c|c|c|c|c|c|c|}
\hline \multirow[t]{2}{*}{ Characteristic } & \multicolumn{3}{|l|}{ LD } & \multicolumn{3}{|l|}{ ED } \\
\hline & $\begin{array}{l}\text { High-CXI group } \\
(n=83)\end{array}$ & $\begin{array}{l}\text { Low-CXI group } \\
(n=24)\end{array}$ & $p$ & $\begin{array}{l}\text { High-CXI group } \\
(n=123)\end{array}$ & $\begin{array}{l}\text { Low-CXI group } \\
(n=37)\end{array}$ & $p$ \\
\hline Age & & & 0.067 & & & 0.214 \\
\hline$<70$ years & $52(62.7 \%)$ & $10(41.7 \%)$ & & $69(56.1 \%)$ & $25(67.6 \%)$ & \\
\hline$\geq 70$ years & $31(37.4 \%)$ & $14(58.3 \%)$ & & $54(43.9 \%)$ & $12(32.4 \%)$ & \\
\hline Median (IQR), years & $66(61-71)$ & $70.5(66-76.5)$ & 0.033 & $68(61-74)$ & $68(64-71)$ & 0.754 \\
\hline ECOG PS & & & 0.008 & & & 0.013 \\
\hline $0-1$ & $74(89.2 \%)$ & $16(66.7 \%)$ & & $98(79.7 \%)$ & $22(59.5 \%)$ & \\
\hline $2-3$ & $9(10.8 \%)$ & $8(33.3 \%)$ & & $25(20.3 \%)$ & $15(40.5 \%)$ & \\
\hline Smoking status & & & 0.400 & & & $>0.998$ \\
\hline Never-smoker & $1(1.2 \%)$ & $1(4.2 \%)$ & & $2(1.6 \%)$ & $0(0.0 \%)$ & \\
\hline Current/former smoker & $82(98.8 \%)$ & $23(95.8 \%)$ & & $121(98.4 \%)$ & $37(100.0 \%)$ & \\
\hline Regimen & & & 0.224 & & & 0.242 \\
\hline Etoposide and platinum & $83(100.0 \%)$ & $23(95.8 \%)$ & & $114(92.7 \%)$ & $32(86.5 \%)$ & \\
\hline Irinotecan and cisplatin & $0(0.0 \%)$ & $1(4.2 \%)$ & & $9(7.3 \%)$ & $5(13.5 \%)$ & \\
\hline Prophylactic cranial irradiation & & & 0.132 & & & 0.006 \\
\hline Yes & $49(59.0 \%)$ & $10(41.7 \%)$ & & $50(40.7 \%)$ & $6(16.2 \%)$ & \\
\hline No & $34(41.0 \%)$ & $14(58.3 \%)$ & & $73(59.4 \%)$ & $31(83.8 \%)$ & \\
\hline $\begin{array}{l}\text { Lactate dehydrogenase status ( } n=72 \text { in LD, } \\
n=133 \text { in ED) }\end{array}$ & & & 0.339 & & & 0.474 \\
\hline Normal & $31(57.4 \%)$ & $8(44.4 \%)$ & & $34(34.0 \%)$ & $9(27.3 \%)$ & \\
\hline Elevated & $23(42.6 \%)$ & $10(55.6 \%)$ & & $66(66.0 \%)$ & $24(72.7 \%)$ & \\
\hline Median BMI (IQR), kg/m² & $23.0(20.8-25.2)$ & $21.9(20.1-23.8)$ & 0.104 & $22.6(20.7-24.5)$ & $21.0(19.9-22.5)$ & 0.007 \\
\hline
\end{tabular}

$L D$ limited-stage disease, $E D$ extensive-stage disease, $C X I$ cachexia index, IQR interquartile range, ECOG PS Eastern Cooperative Oncology Group performance status, $B M I$ body mass index 
Table 2 Treatment responses

\begin{tabular}{|c|c|c|c|c|c|c|}
\hline \multirow[t]{2}{*}{ Treatment response } & \multicolumn{3}{|l|}{ LD } & \multicolumn{3}{|l|}{ ED } \\
\hline & $\begin{array}{l}\text { High-CXI group }(n= \\
\text { 83) }\end{array}$ & $\begin{array}{l}\text { Low-CXI group }(n= \\
\text { 24) }\end{array}$ & $p$ & $\begin{array}{l}\text { High-CXI group }(n= \\
123)\end{array}$ & $\begin{array}{l}\text { Low-CXI group }(n= \\
37)\end{array}$ & $p$ \\
\hline Complete response (CR) & $30(36.1 \%)$ & $1(4.2 \%)$ & 0.004 & $2(1.6 \%)$ & $0(0.0 \%)$ & $<0.001$ \\
\hline Partial response (PR) & $49(59.0 \%)$ & $18(75.0 \%)$ & & $103(83.7 \%)$ & $20(54.1 \%)$ & \\
\hline $\begin{array}{l}\text { Stable disease or progressive } \\
\text { disease }\end{array}$ & $1(1.2 \%)$ & $2(8.3 \%)$ & & $15(12.2 \%)$ & $10(27.0 \%)$ & \\
\hline Not available & $3(3.6 \%)$ & $3(12.5 \%)$ & & $3(2.4 \%)$ & 7 (18.9\%) & \\
\hline Objective response rate $(C R+P R)$ & 79 (95.2\%) & 19 (79.2\%) & 0.026 & $105(85.4 \%)$ & $20(54.1 \%)$ & $<0.001$ \\
\hline
\end{tabular}

$L D$ limited-stage disease, $E D$ extensive-stage disease, $C X I$ cachexia index

toxicity between the low- and high-CXI groups. However, low-CXI patients received fewer cycles of chemotherapy (median 3 vs. 6 cycles, respectively, $p<0.001$, for ED patients) and discontinued treatment early because of treatment-related toxicity more frequently (37.5\% vs. $16.9 \%$, respectively, $p=0.030$, for LD patients; $27.0 \%$ vs. $11.4 \%, p=0.019$, for ED patients) compared to high-CXI patients. TRM tended to occur more frequently in the low-CXI group than in the high-CXI group for ED patients $(10.8 \%$ vs. $2.4 \%$, respectively, $p=$ $0.051)$.

\section{Survival}

The median follow-up duration was 41 months. Similar findings were obtained regardless of stage. In LD, patients with a low CXI had a shorter PFS (median 6.3 vs. 11.1 months, respectively, $p<0.001$; Fig. 1a) and OS (median 7.5 vs. 20.6 months, respectively, $p<0.001$; Fig. 1b) compared to those with a high CXI. In ED, patients with a low CXI also had a shorter PFS (median 2.9 vs. 6.3 months, respectively, $p<0.001$; Fig. 1c) and OS (median 5.8 vs. 12.8 months, respectively, $p<0.001$; Fig. $1 \mathrm{~d}$ ) compared to those with a high CXI.

On multivariate analysis, a low CXI was an independent poor prognostic factor for PFS [low CXI, hazard ratio (HR) 2.445, 95\% CI 1.406-4.253, $p=0.002]$ and OS (low CXI, HR 2.393, 95\% CI 1.372-4.174, $p=0.002$ ) in LD patients. In ED patients, an ECOG PS of 2-3 and a low CXI were independent poor prognostic factors for PFS (low CXI, HR 1.764, 95\% CI 1.195-2.604, $p=0.004$ ) and OS (low CXI, HR 2.269, 95\% CI 1.529-3.366, $p<0.001$ ) (Table 4).

\section{Discussion}

This is the first study to report that a low CXI is closely related to poor clinical outcomes in SCLC patients. The $\mathrm{CR}$ rate and ORR differed greatly between the low- and high-CXI groups. Although the ECOG PS, which is an important prognostic factor, was not balanced between the two groups, PFS and OS were much poorer in the low-CXI group even after adjusting for the PS. Although the role for the CXI has not yet been examined in SCLC patients, each CXI factor has been suggested to be prognostic in several studies. Sarcopenic SCLC patients experienced poorer survival than non-sarcopenic patients [18]. When models that included both sarcopenia and levels of inflammatory markers were used, the clinical significance of sarcopenia was emphasized [19, 29]. Hypoalbuminemia and other indices reflecting low serum albumin levels were associated with reduced survival, increased treatment-related toxicity, and a low treatment response rate [21, 22, 30-32]. A high NLR was related to

Table 3 Treatment-related toxicity and treatment compliance

\begin{tabular}{|c|c|c|c|c|c|c|}
\hline \multirow[t]{2}{*}{ Adverse event } & \multicolumn{3}{|l|}{ LD } & \multicolumn{3}{|l|}{ ED } \\
\hline & $\begin{array}{l}\text { High-CXI group } \\
(n=83)\end{array}$ & $\begin{array}{l}\text { Low-CXI group } \\
(n=24)\end{array}$ & $p$ & $\begin{array}{l}\text { High-CXI group } \\
(n=123)\end{array}$ & $\begin{array}{l}\text { Low-CXI group } \\
(n=37)\end{array}$ & $p$ \\
\hline \multicolumn{7}{|l|}{ Hematological toxicity $\geq$ grade 3} \\
\hline Anemia & $17(20.5 \%)$ & $7(29.2 \%)$ & 0.369 & $21(17.1 \%)$ & $9(24.3 \%)$ & 0.322 \\
\hline Neutropenia & $78(94.0 \%)$ & $21(87.5 \%)$ & 0.375 & $108(87.8 \%)$ & $29(78.4 \%)$ & 0.152 \\
\hline Febrile neutropenia & $16(19.3 \%)$ & $5(20.8 \%)$ & $>0.998$ & $17(13.8 \%)$ & $8(21.6 \%)$ & 0.252 \\
\hline Thrombocytopenia & $21(25.3 \%)$ & $7(29.2 \%)$ & 0.704 & $27(22.0 \%)$ & $10(27.0 \%)$ & 0.521 \\
\hline Median treatment cycles (IQR) & $6(4-6)$ & $5.5(3-6)$ & 0.118 & $6(4-6)$ & $3(2-6)$ & $<0.001$ \\
\hline Early discontinuation of treatment & $14(16.9 \%)$ & $9(37.5 \%)$ & 0.030 & $14(11.4 \%)$ & $10(27.0 \%)$ & 0.019 \\
\hline Treatment-related mortality & $4(4.8 \%)$ & $3(12.5 \%)$ & 0.186 & $3(2.4 \%)$ & $4(10.8 \%)$ & 0.051 \\
\hline
\end{tabular}

$L D$ limited-stage disease, $E D$ extensive-stage disease, $C X I$ cachexia index, IQR interquartile range 
(A)

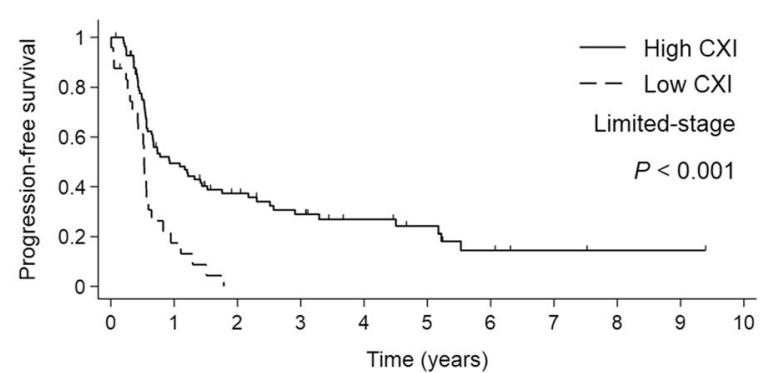

(C)

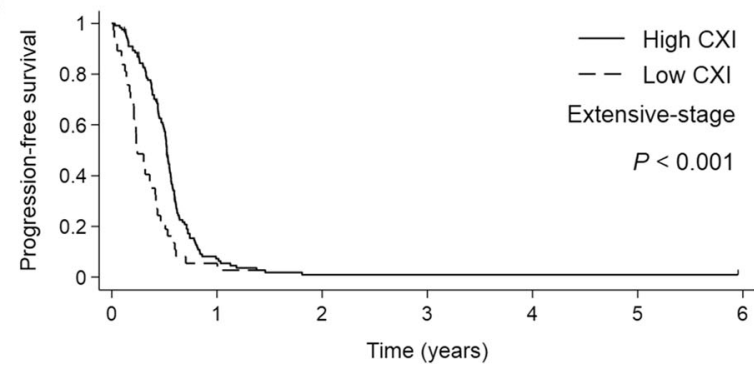

(B)

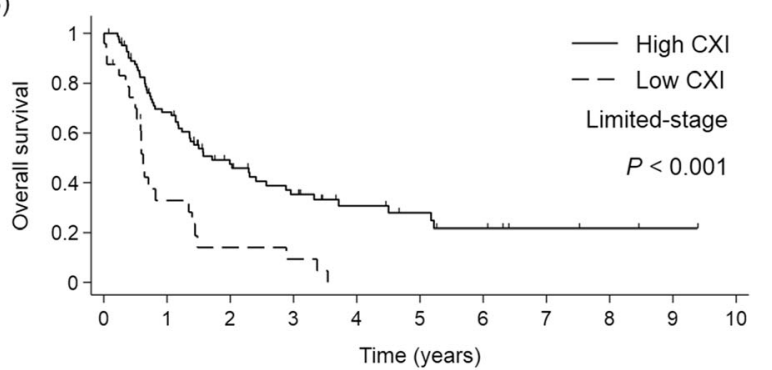

(D)

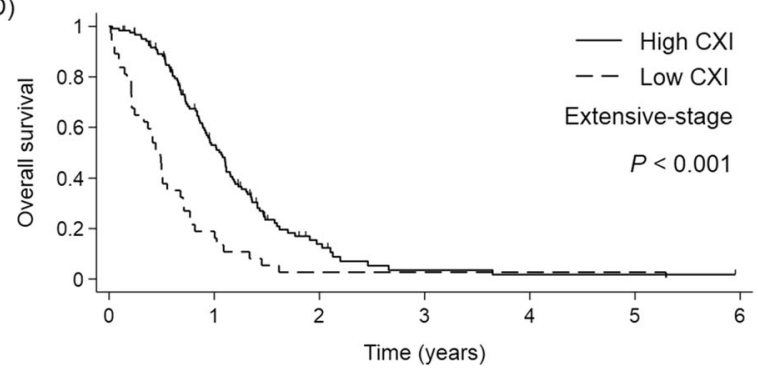

Fig. 1 Kaplan-Meier curves for $(\mathbf{a}, \mathbf{c})$ progression-free survival and (b, d) overall survival according to the cachexia index (CXI) and tumor stage

poor PS, a high probability of recurrence, and reduced survival [33-35]. The results of the present study and previous studies thus suggest that the CXI is significantly prognostic in SCLC patients.

Cancer cachexia must be carefully assessed. Percentage weight loss alone is of limited utility in the era of obesity [36, 37]. Sarcopenia has been used to diagnose and stage cancer cachexia [11]. Cross-sectional CT optimally assesses muscle mass [11]. Inflammatory cytokines produced by tumor cells [tumor necrosis factor (TNF)-a, interleukin (IL)-6, and IL-8] contribute to muscle wasting by inducing oxidative stress in skeletal muscles and activating muscle degradation pathways [38-40]. TNF-a inhibited albumin expression in a murine model of cachexia even before the onset of weight loss [41]. Ideal biomarkers of cancer cachexia must therefore reflect these various processes. Several studies have explored the clinical utilities of composite biomarkers or scoring systems for cachexia in SCLC patients [20-22, 32]. However, unlike the CXI, the biomarkers did not consider either sarcopenia or systemic inflammation. Although the CXI is more complex than other biomarkers, the factors can be measured non-invasively via routine baseline imaging and laboratory tests. The CXI may serve as an ideal biomarker of cachexia in SCLC patients.

The low-CXI group very frequently discontinued treatment early because of treatment-related toxicity and suffered a higher rate of TRM. A recent study reported that malnourished patients exhibited increased rates of toxicity of grade $\geq 3$ and were more likely to be hospitalized in phase I and II oncology clinical trials [42]. Several studies found that sarcopenia is a significant predictor of dose-limiting toxicity in patients with various malignancies [43-46]. Chemotherapy doses are generally based on body surface area. Therefore, among patients of the same height and weight, sarcopenic patients receive relatively higher doses than do non-sarcopenic patients because drug metabolism occurs predominantly in lean body tissue [37]. Given that no patient who did not complete planned treatment achieved a CR, the treatment intolerance observed in the low-CXI group may be associated with a poor response to chemotherapy.

Our work had several limitations. First, the data were collected retrospectively and thus associated with a risk of selection bias. We also lacked detailed toxicity profiles. Second, the utility of the CXI in female patients could not be assessed in this study. Third, the method used to measure the SMI in the present study was different from the methods used in previous studies, and calculation of the CXI using the SMI of pectoralis muscle was not validated in SCLC, rendering comparisons difficult. Given the low sensitivity of the CXI cutoffs in the present study, validation of our methodological approach is essential. In the original study, Jafri et al. calculated the CXI and SMI using the skeletal muscle area as determined on abdominal CT in non-small cell lung cancer patients [23]. In our institution, abdominal CT is not a routine staging work-up for SCLC, and chest CT does not generally include the L3 level, which is the standard level use for calculation of the SMI. Instead, we examined the pectoralis muscle at the T4 level to calculate the SMI. In previous studies, SMIs calculated using muscles at other vertebral levels, or the pectoralis muscle, were strongly correlated with the L3-SMI [47-49]. In 
Table 4 Cox's regression analysis for PFS and OS

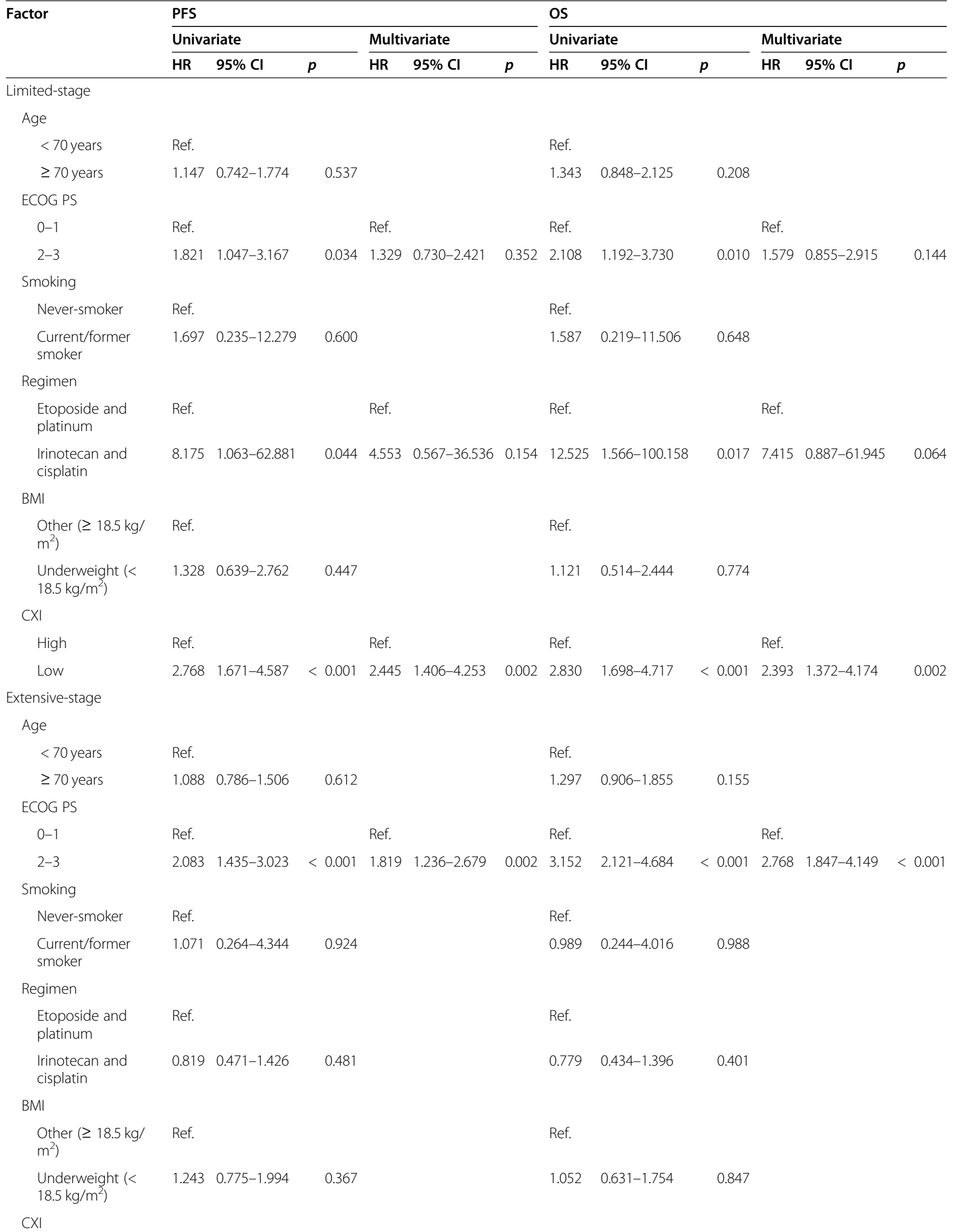


Table 4 Cox's regression analysis for PFS and OS (Continued)

\begin{tabular}{|c|c|c|c|c|c|c|c|c|c|c|c|c|}
\hline \multirow[t]{3}{*}{ Factor } & \multicolumn{6}{|l|}{ PFS } & \multicolumn{6}{|l|}{ os } \\
\hline & \multicolumn{3}{|c|}{ Univariate } & \multicolumn{3}{|c|}{ Multivariate } & \multicolumn{3}{|c|}{ Univariate } & \multicolumn{3}{|c|}{ Multivariate } \\
\hline & HR & $95 \% \mathrm{Cl}$ & $p$ & HR & $95 \% \mathrm{Cl}$ & $p$ & $\overline{H R}$ & $95 \% \mathrm{Cl}$ & $p$ & $\overline{H R}$ & $95 \% \mathrm{Cl}$ & $p$ \\
\hline High & Ref. & & & Ref. & & & Ref. & & & Ref. & & \\
\hline Low & 2.039 & $1.401-2.967$ & $<0.001$ & 1.764 & $1.195-2.604$ & 0.004 & 2.644 & $1.796-3.894$ & $<0.001$ & 2.269 & $1.529-3.366$ & $<0.001$ \\
\hline
\end{tabular}

PFS progression-free survival, OS overall survival, HR hazard ratio, Cl confidence interval, ECOG PS Eastern Cooperative Oncology Group performance status, BMI body mass index, CXI cachexia index

addition, previous studies used the median to determine the CXI cutoff [23, 24]. The time-dependent ROC analysis employed in the present study is an efficient means of measuring the performance of a biomarker at a certain time point with survival data compared with other methods, although censoring is still problematic [26]. Further large prospective studies are needed to validate our methodological approach and confirm the clinical applicability of the CXI in SCLC.

In conclusion, we found that cachectic patients with low CXIs more frequently discontinued treatment early and exhibited poor prognosis in SCLC. Intensive supportive care, including aggressive nutritional support and dose adjustment, may improve the treatment outcomes of SCLC patients with a low CXI receiving chemotherapy or chemoradiotherapy. We anticipate that the CXI may be adopted as an ideal biomarker for research on cancer cachexia and that its measurement will be integrated into routine practice for the diagnostic work-up for SCLC after validation through further prospective studies.

\section{Abbreviations}

AUC: Area under the curve; BMI: Body mass index; Cl: Confidence interval; CR: Complete response; CT: Computed tomography; CXI: Cachexia index; ECOG PS: Eastern Cooperative Oncology Group performance status; ED: Extensive-stage disease; HR: Hazard ratio; IL: Interleukin; LD: Limited-stage disease; NLR: Neutrophil-to-lymphocyte ratio; ORR: Objective response rate; OS: Overall survival; PFS: Progression-free survival; PR: Partial response; RECI ST: Response Evaluation Criteria in Solid Tumors; ROC: Receiver operating characteristic; SCLC: Small-cell lung cancer; SMI: Skeletal muscle index; TNF: Tumor necrosis factor; TRM: Treatment-related mortality

\section{Supplementary Information}

The online version contains supplementary material available at https://doi. org/10.1186/s12885-021-08300-x.

Additional file 1. Time-dependent receiver operating characteristic (ROC) curve of the cachexia index (CXI) for prediction of (A) 18-month overall survival in limited-stage disease (LD) and (B) 10-month overall survival in extensive-stage disease (ED). Circles indicate CXIs of (A) 5.82 in LD and (B) 3.83 in ED. These cutoffs were determined by maximizing the Youden index.

\section{Acknowledgements}

This work was supported by the Ministry of Education of Republic of Korea and the National Research Foundation of Korea (NFR-

2019S1A5A2A03041296).

\section{Authors' contributions}

Study conceptualization and design: SG and GL. Data collection: SG, MJP and GL. Data analysis and interpretation: SG, MJP, and GL. Overall supervision: GL. Manuscript writing: SG, MJP and GL. All authors have read, revised, and approved the manuscript.

\section{Funding}

This work was supported by the Ministry of Education of Republic of Korea and the National Research Foundation of Korea (NFR-

2019S1A5A2A03041296).

\section{Availability of data and materials}

The datasets used and/or analyzed during the current study are available from the corresponding author on reasonable request.

\section{Declarations}

\section{Ethics approval and consent to participate}

This study was approved by the Institutional Review Board of Gyeongsang National University Hospital and conducted in accordance with the Good Clinical Practice guidelines and the Declaration of Helsinki. The informed consent was waived by the Institutional Review Board of Gyeongsang National University Hospital.

\section{Consent for publication}

Not applicable.

\section{Competing interests}

The authors declare that they have no competing interests.

\section{Author details}

${ }^{1}$ Division of Hematology-Oncology, Department of Internal Medicine, Institute of Health Science, Gyeongsang National University Changwon Hospital, Gyeongsang National University College of Medicine, Changwon, Republic of Korea. ${ }^{2}$ Department of Radiology, Gyeongsang National University Hospital, Gyeongsang National University College of Medicine, Jinju, Republic of Korea. ${ }^{3}$ Division of Hematology-Oncology, Department of Internal Medicine, Institute of Health Science, Gyeongsang National University Hospital, Gyeongsang National University College of Medicine, 79 Gangnam-ro, Jinju 52727, Republic of Korea.

Received: 2 February 2021 Accepted: 4 May 2021

Published online: 17 May 2021

\section{References}

1. Gazdar AF, Bunn PA, Minna JD. Small-cell lung cancer: what we know, what we need to know and the path forward. Nat Rev Cancer. 2017;17(12):72537. https://doi.org/10.1038/nrc.2017.87.

2. Sabari JK, Lok BH, Laird JH, Poirier JT, Rudin CM. Unravelling the biology of SCLC: implications for therapy. Nat Rev Clin Oncol. 2017;14(9):549-61. https://doi.org/10.1038/nrclinonc.2017.71.

3. Noda K, Nishiwaki Y, Kawahara M, Negoro S, Sugiura T, Yokoyama A, et al. Irinotecan plus cisplatin compared with etoposide plus cisplatin for extensive small-cell lung cancer. N Engl J Med. 2002;346(2):85-91. https:// doi.org/10.1056/NEJMoa003034.

4. Kubota K, Hida T, Ishikura S, Mizusawa J, Nishio M, Kawahara M, et al. Etoposide and cisplatin versus irinotecan and cisplatin in patients with limited-stage small-cell lung cancer treated with etoposide and cisplatin plus concurrent accelerated hyperfractionated thoracic radiotherapy 
(JCOG0202): a randomised phase 3 study. Lancet Oncol. 2014;15(1):106-13. https://doi.org/10.1016/S1470-2045(13)70511-4

5. Kim DW, Kim HG, Kim JH, Park K, Kim HK, Jang JS, et al. Randomized phase III trial of Irinotecan plus Cisplatin versus Etoposide plus Cisplatin in chemotherapy-naive Korean patients with extensive-disease small cell lung Cancer. Cancer Res Treat. 2019;51(1):119-27. https://doi.org/10.4143/crt.2018. 019

6. Horn L, Mansfield AS, Szczesna A, et al. First-line Atezolizumab plus chemotherapy in extensive-stage small-cell lung Cancer. N Engl J Med. 2018:379(23):2220-9. https://doi.org/10.1056/NEJMoa1809064.

7. Paz-Ares L, Dvorkin M, Chen Y, Reinmuth N, Hotta K, Trukhin D, et al. Durvalumab plus platinum-etoposide versus platinum-etoposide in first-line treatment of extensive-stage small-cell lung cancer (CASPIAN): a randomised, controlled, open-label, phase 3 trial. Lancet. 2019;394(10212): 1929-39. https://doi.org/10.1016/S0140-6736(19)32222-6.

8. Christodoulou M, Blackhall F, Mistry H, Leylek A, Knegjens J, Remouchamps $V$, et al. Compliance and outcome of elderly patients treated in the concurrent once-daily versus twice-daily radiotherapy (CONVERT) trial. J Thorac Oncol. 2019;14(1):63-71. https://doi.org/10.1016/j.jtho.2018.09.027.

9. Schild SE, Zhao L, Wampfler JA, Daniels TB, Sio T, Ross HJ, et al. Small-cell lung Cancer in very elderly ( $>/=80$ years) patients. Clin Lung Cancer. 2019; 20(4):313-21. https://doi.org/10.1016/j.cllc.2019.05.007.

10. Janssen-Heijnen ML, Maas HA, Koning CC, van der Bruggen-Bogaarts BA, Groen HJ, Wymenga AN. Tolerance and benefits of treatment for elderly patients with limited small-cell lung cancer. J Geriatr Oncol. 2014;5(1):71-7. https://doi.org/10.1016/j.jgo.2013.07.008.

11. Fearon K, Strasser F, Anker SD, Bosaeus I, Bruera E, Fainsinger RL, et al. Definition and classification of cancer cachexia: an international consensus. Lancet Oncol. 2011;12(5):489-95. https://doi.org/10.1016/S1470-2045(1 0)70218-7.

12. da Rocha IMG, Marcadenti A, de Medeiros GOC, et al. Is cachexia associated with chemotherapy toxicities in gastrointestinal cancer patients? A prospective study. J Cachexia Sarcopenia Muscle. 2019;10(2):445-54. https:// doi.org/10.1002/jcsm.12391

13. Kasvis $P$, Vigano $M$, Vigano A. Health-related quality of life across cancer cachexia stages. Ann Palliat Med. 2019;8(1):33-42. https://doi.org/10.21037/a pm.2018.08.04.

14. Martin L, Birdsell L, Macdonald N, et al. Cancer cachexia in the age of obesity: skeletal muscle depletion is a powerful prognostic factor, independent of body mass index. J Clin Oncol. 2013;31(12):1539-47. https:// doi.org/10.1200/JCO.2012.45.2722.

15. Bremnes RM, Sundstrom $S$, Aasebo $U$, et al. The value of prognostic factors in small cell lung cancer: results from a randomised multicenter study with minimum 5 year follow-up. Lung Cancer. 2003;39(3):303-13. https://doi, org/10.1016/S0169-5002(02)00508-1.

16. Bernhard J, Hurny C, Bacchi M, et al. Initial prognostic factors in small-cell lung cancer patients predicting quality of life during chemotherapy. Swiss Group for Clinical Cancer Research (SAKK). Br J Cancer. 1996;74(10):1660-7. https://doi.org/10.1038/bjc.1996.606

17. Christodolou C, Pavlidis N, Samantas E, Fountzilas G, Kouvatseas G, Pagdatoglou K, et al. Prognostic factors in Greek patients with small cell lung cancer (SCLC). A Hellenic cooperative oncology group study. Anticancer Res. 2002;22(6B):3749-57.

18. Kim EY, Kim YS, Park I, Ahn HK, Cho EK, Jeong YM. Prognostic significance of CT-determined sarcopenia in patients with small-cell lung Cancer. J Thorac Oncol. 2015;10(12):1795-9. https://doi.org/10.1097/JTO.0000000000000690.

19. Go SI, Park MJ, Song HN, Kang MH, Park HJ, Jeon KN, et al. Sarcopenia and inflammation are independent predictors of survival in male patients newly diagnosed with small cell lung cancer. Support Care Cancer. 2016;24(5): 2075-84. https://doi.org/10.1007/s00520-015-2997-X.

20. Kim EY, Lee HY, Kim YS, et al. Prognostic significance of cachexia score assessed by $\mathrm{CT}$ in male patients with small cell lung cancer. Eur J Cancer Care (Engl). 2018;27(1):e12695. https://doi.org/10.1111/ecc.12695.

21. Go Sl, Jeon H, Park SW, Kang MH, Kim HG, Lee GW. Low pre-treatment nutritional index is significantly related to poor outcomes in small cell lung cancer. Thorac Cancer. 2018;9(11):1483-91. https://doi.org/10.1111/17597714.12862 .

22. Lee GW, Go SI, Kim DW, Kim HG, Kim JH, An HJ, et al. Geriatric nutritional risk index as a prognostic marker in patients with extensive-stage disease small cell lung cancer: results from a randomized controlled trial. Thorac Cancer. 2020;11(1):62-71. https://doi.org/10.1111/1759-7714.13229.
23. Jafri SH, Previgliano C, Khandelwal K, Shi R. Cachexia index in advanced non-small-cell lung Cancer patients. Clin Med Insights Oncol. 2015;9:87-93. https://doi.org/10.4137/CMO.S30891.

24. Karmali R, Alrifai T, Fughhi IAM, Ng R, Chukkapalli V, Shah P, et al. Impact of cachexia on outcomes in aggressive lymphomas. Ann Hematol. 2017;96(6): 951-6. https://doi.org/10.1007/s00277-017-2958-1.

25. Eisenhauer EA, Therasse P, Bogaerts J, Schwartz LH, Sargent D, Ford R, et al. New response evaluation criteria in solid tumours: revised RECIST guideline (version 1.1). Eur J Cancer. 2009;45(2):228-47. https://doi.org/10.1016/j.ejca.2 008.10.026.

26. Kamarudin AN, Cox T, Kolamunnage-Dona R. Time-dependent ROC curve analysis in medical research: current methods and applications. BMC Med Res Methodol. 2017;17(1):53. https://doi.org/10.1186/s12874-017-0332-6.

27. Bonner JA, Sloan JA, Shanahan TG, Brooks BJ, Marks RS, Krook JE, et al. Phase III comparison of twice-daily split-course irradiation versus once-daily irradiation for patients with limited stage small-cell lung carcinoma. J Clin Oncol. 1999:17(9):2681-91. https://doi.org/10.1200/JCO.1999.17.9.2681.

28. Corso CD, Rutter CE, Park HS, Lester-Coll NH, Kim AW, Wilson LD, et al. Role of Chemoradiotherapy in elderly patients with limited-stage small-cell lung Cancer. J Clin Oncol. 2015;33(36):4240-6. https://doi.org/10.1200/JCO.2015. 62.4270.

29. Kim EY, Kim YS, Seo JY, Park I, Ahn HK, Jeong YM, et al. The relationship between sarcopenia and systemic inflammatory response for Cancer Cachexia in small cell lung Cancer. PLoS One. 2016;11(8):e0161125. https:// doi.org/10.1371/journal.pone.0161125.

30. Zhou T, Zhan J, Hong S, Hu Z, Fang W, Qin T, et al. Ratio of C-reactive protein/albumin is an inflammatory prognostic score for predicting overall survival of patients with small-cell lung Cancer. Sci Rep. 2015;5(1):10481. https://doi.org/10.1038/srep10481.

31. Kim EY, Kim N, Kim YS, Seo JY, Park I, Ahn HK, et al. Prognostic significance of modified advanced lung Cancer inflammation index (ALI) in patients with small cell lung Cancer_comparison with original ALI. PLoS One. 2016; 11(10):e0164056. https://doi.org/10.1371/journal.pone.0164056.

32. Kurishima K, Watanabe H, Ishikawa H, Satoh H, Hizawa N. Modified Glasgow prognostic score in patients with small-cell lung cancer. Mol Clin Oncol. 2017;7(1):121-4. https://doi.org/10.3892/mco.2017.1261.

33. Kang MH, Go Sl, Song HN, Lee A, Kim SH, Kang JH, et al. The prognostic impact of the neutrophil-to-lymphocyte ratio in patients with small-cell lung cancer. Br J Cancer. 2014;111(3):452-60. https://doi.org/10.1038/bjc.2 014.317.

34. Shao N, Cai Q. High pretreatment neutrophil-lymphocyte ratio predicts recurrence and poor prognosis for combined small cell lung cancer. Clin Transl Oncol. 2015;17(10):772-8. https://doi.org/10.1007/s12094-01 5-1289-8.

35. Liu D, Huang Y, Li L, Song J, Zhang L, Li W. High neutrophil-to-lymphocyte ratios confer poor prognoses in patients with small cell lung cancer. BMC Cancer. 2017;17(1):882. https://doi.org/10.1186/s12885-017-3893-1.

36. Martin L, Senesse P, Gioulbasanis I, Antoun S, Bozzetti F, Deans C, et al. Diagnostic criteria for the classification of cancer-associated weight loss. J Clin Oncol. 2015;33(1):90-9. https://doi.org/10.1200/JCO.2014.56.1894.

37. Prado CM, Cushen SJ, Orsso CE, Ryan AM. Sarcopenia and cachexia in the era of obesity: clinical and nutritional impact. Proc Nutr Soc. 2016;75(2):18898. https://doi.org/10.1017/S0029665115004279.

38. Hou YC, Wang CJ, Chao YJ, et al. Elevated Serum Interleukin-8 Level Correlates with Cancer-Related Cachexia and Sarcopenia: An Indicator for Pancreatic Cancer Outcomes. J Clin Med. 2018;7(12):502. https://doi.org/1 0.3390/jcm7120502.

39. Abrigo J, Elorza AA, Riedel CA, et al. Role of oxidative stress as key regulator of muscle wasting during Cachexia. Oxidative Med Cell Longev. 2018;2018:2063179.

40. Narsale AA, Carson JA. Role of interleukin-6 in cachexia: therapeutic implications. Curr Opin Support Palliat Care. 2014;8(4):321-7. https://doi. org/10.1097/SPC.0000000000000091.

41. Brenner DA, Buck M, Feitelberg SP, Chojkier M. Tumor necrosis factor-alpha inhibits albumin gene expression in a murine model of cachexia. J Clin Invest. 1990;85(1):248-55. https://doi.org/10.1172/JCl114419.

42. Jain R, Handorf E, Khare V, Blau M, Chertock Y, Hall MJ. Impact of baseline nutrition and exercise status on toxicity and outcomes in phase I and II oncology clinical trial participants. Oncologist. 2020;25(2):161-9. https://doi. org/10.1634/theoncologist.2019-0289.

43. Prado CM, Baracos VE, McCargar $L$, et al. Body composition as an independent determinant of 5-fluorouracil-based chemotherapy toxicity. 
Clin Cancer Res. 2007;13(11):3264-8. https://doi.org/10.1158/1078-0432.CCR06-3067.

44. Prado CM, Baracos VE, McCargar LJ, et al. Sarcopenia as a determinant of chemotherapy toxicity and time to tumor progression in metastatic breast cancer patients receiving capecitabine treatment. Clin Cancer Res. 2009; 15(8):2920-6. https://doi.org/10.1158/1078-0432.CCR-08-2242.

45. Antoun S, Birdsell L, Sawyer MB, Venner P, Escudier B, Baracos VE. Association of skeletal muscle wasting with treatment with sorafenib in patients with advanced renal cell carcinoma: results from a placebocontrolled study. J Clin Oncol. 2010;28(6):1054-60. https://doi.org/10.1200/ JCO.2009.24.9730

46. Tan BH, Brammer K, Randhawa N, et al. Sarcopenia is associated with toxicity in patients undergoing neo-adjuvant chemotherapy for oesophagogastric cancer. Eur J Surg Oncol. 2015;41(3):333-8. https://doi.org/10.1016/j. ejso.2014.11.040

47. Kim EY, Kim YS, Park I, Ahn HK, Cho EK, Jeong YM, et al. Evaluation of sarcopenia in small-cell lung cancer patients by routine chest CT. Support Care Cancer. 2016;24(11):4721-6. https://doi.org/10.1007/s00520-016-3321-0.

48. Go SI, Park MJ, Song HN, Kim HG, Kang MH, Kang JH, et al. A comparison of pectoralis versus lumbar skeletal muscle indices for defining sarcopenia in diffuse large B-cell lymphoma - two are better than one. Oncotarget. 2017; 8(29):47007-19. https://doi.org/10.18632/oncotarget. 16552.

49. Derstine BA, Holcombe SA, Ross BE, Wang NC, Su GL, Wang SC. Skeletal muscle cutoff values for sarcopenia diagnosis using T10 to $L 5$ measurements in a healthy US population. Sci Rep. 2018;8(1):11369. https:// doi.org/10.1038/s41598-018-29825-5.

\section{Publisher's Note}

Springer Nature remains neutral with regard to jurisdictional claims in published maps and institutional affiliations.

Ready to submit your research? Choose BMC and benefit from:

- fast, convenient online submission

- thorough peer review by experienced researchers in your field

- rapid publication on acceptance

- support for research data, including large and complex data types

- gold Open Access which fosters wider collaboration and increased citations

- maximum visibility for your research: over $100 \mathrm{M}$ website views per year

At $\mathrm{BMC}$, research is always in progress.

Learn more biomedcentral.com/submissions 